\title{
Editorial
}

\section{Entropy Best Paper Award 2013}

\section{Kevin H. Knuth}

Department of Physics and Department of Informatics, University at Albany, 1400 Washington Avenue, Albany, NY 12222, USA; E-Mail: kknuth@albany.edu; Tel.: +1-518-442-4653;

Fax: $+1-518-442-5260$

Received: 16 February 2013 / Accepted: 16 February 2013 / Published: 20 February 2013

The journal Entropy is initiating a "Best Paper" award to recognize outstanding papers in the area of entropy and information studies published in Entropy. We are pleased to announce the first "Entropy Best Paper Award" for 2013. Nominations were selected by the Editor-in-Chief and selected Editorial Board Members from all the papers published in 2009 and evaluated by the Entropy Best Paper Award Committee. Reviews and articles were evaluated separately. A first prize is awarded to the selected review paper, and a first and second prize is awarded to the top two selected research articles. We proudly announce that the following three papers have won the Entropy Best Paper Award in 2013:

\section{Article Award:}

$1^{\text {st }}$ Prize

\section{Bhashyam Balaji}

Continuous-Discrete Path Integral Filtering

Entropy 2009, 11(3), 402-430; doi:10.3390/e110300402

Available online: http://www.mdpi.com/1099-4300/11/3/402

$2^{\text {nd }}$ Prize

Arto Annila and Stanley Salthe

Economies Evolve by Energy Dispersal

Entropy 2009, 11(4), 606-633; doi:10.3390/e11040606

Available online: http://www.mdpi.com/1099-4300/11/4/606

\section{Review Award:}

\section{Michel Feidt}

Optimal Thermodynamics-New Upperbounds

Entropy 2009, 11(4), 529-547; doi:10.3390/e11040529

Available online: http://www.mdpi.com/1099-4300/11/4/529 
The Entropy Best Paper Award Committee merits the article "Continuous-Discrete Path Integral Filtering" as "a new approach by the Dirac-Feynman path integral filtering algorithm was developed" and that it represents "a combination of a real step forward and good writing". The article "Economies Evolve by Energy Dispersal" demonstrates that "economic activity can be in ways regarded as an evolutionary process governed by the second law of thermodynamics, and thus having a scientific foundation. ... The results will likely aid decision making by suggesting actions that effectively reduce energy gradients". The review "Optimal Thermodynamics-New Upperbounds" provides "a review of modern advances in thermodynamics" and in it "the author considers the inclusion of additional constraints, such as finite size and time, which results in the development of a new branch of thermodynamics called "Finite Dimensions Optimal Thermodynamics (FDOT)".

These three exceptional papers are valuable contributions to Entropy. On behalf of the Entropy Best Paper Award Committee and the Editorial Board of Entropy, we would like to congratulate these authors for their excellent work. In recognition for their accomplishment, Dr. Bhashyam Balaji and Drs. Arto Annila and Stanley Salthe, will receive monetary prizes of $600 \mathrm{CHF}$ and $400 \mathrm{CHF}$, respectively. All authors will be awarded the privilege to publish an additional paper free of charge in open access format in Entropy, after the usual peer-review procedure.

Entropy Best Paper Award Committee:

Editor-in-Chief

Dr. Kevin H. Knuth

Department of Physics and Department of Informatics, University at Albany, 1400 Washington Avenue, Albany NY 12222, USA

E-Mail:kknuth@albany.edu

\section{Editorial Board Members}

Prof. Dr. Marc A. Rosen

Faculty of Engineering and Applied Science, University of Ontario Institute of Technology, 2000 Simcoe Street North, Oshawa, Ontario, L1H 7K4, Canada

E-Mail: marc.rosen@uoit.ca

\section{Dr. Takuya Yamano}

Department of Information Sciences, Faculty of Science, Kanagawa University, 2946,6-233 Tsuchiya, Hiratsuka, Kanagawa 259-1293, Japan

E-Mail: yamano@amy.hi-ho.ne.jp

\section{Prof. Dr. Jay Lawrence}

The James Franck Institute, University of Chicago, Chicago, IL 60637, USA; and Department of Physics and Astronomy, Dartmouth College, Hanover, NH 03755, USA

E-Mail: Jay.Lawrence@Dartmouth.EDU

(C) 2013 by the authors; licensee MDPI, Basel, Switzerland. This article is an open access article distributed under the terms and conditions of the Creative Commons Attribution license (http://creativecommons.org/licenses/by/3.0/). 